
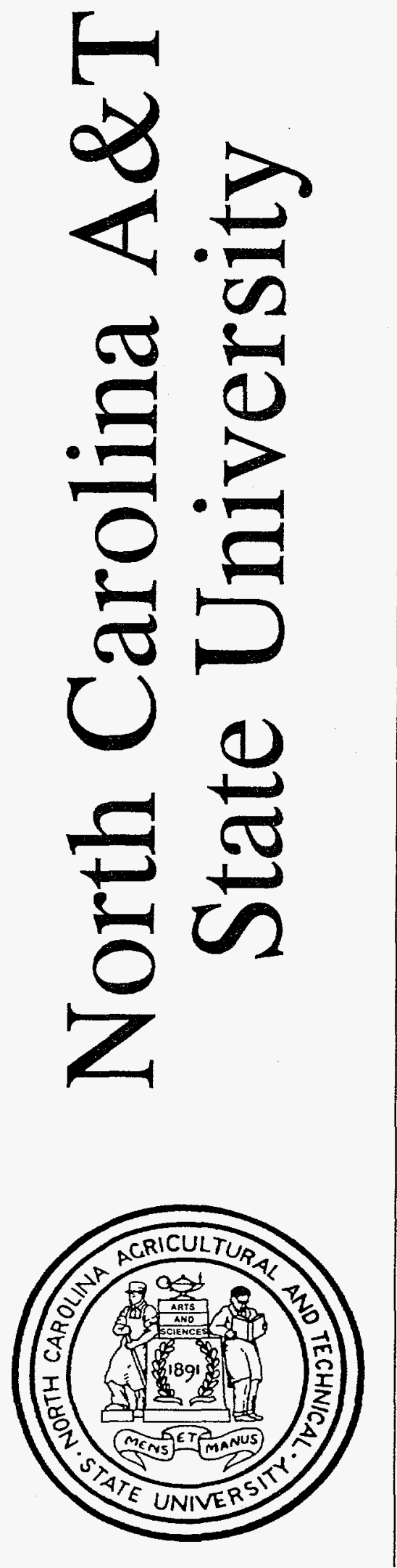

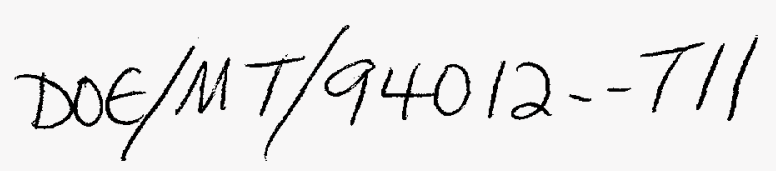

\section{Ignition Rate Measurement of Laser-Ignited Coals}

\author{
Technical Progress Report for period: \\ July $1,199 \not 6$ to September 30,1996 \\ US Department of Energy
}

Grant Number: DE-FG22-94MT94012

Submitted by:

John C. Chen

Assistant Professor

Department of Mechanical Engineering

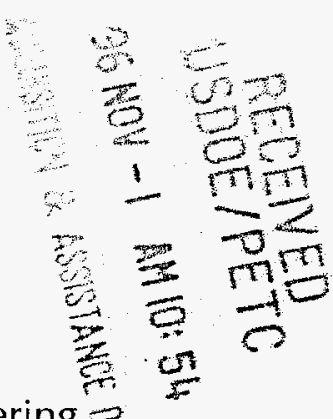

and

Vinayak Kabadi

Associate Professor

Department of Chemical Engineering

October 28, 1996

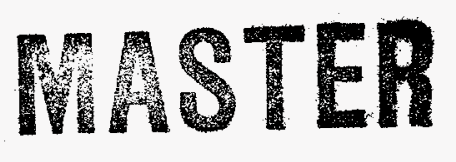

Defpixinton 


\section{DISCLAIMER}

This report was prepared as an account of work sponsored by an agency of the United States Government. Neither the United States Government aor any agency thereof, nor any of their employees, makes any warranty, express or implied, or assumes any legal liability or responsibility for the accuracy, completeness, or usefulness of any information, apparatus, product, or process disclosed, or represents that its use would not infringe privately owned rights. Reference herein to any specific commercial product, process, or service by trade name, trademark, manufacturer, or otherwise does not necessarily constitute or imply its endorsement, recommendation, or favoring by the United States Government or any agency thereof. The views and opinions of authors expressed herein do not necessarily state or reflect those of the United States Government or any agency thereof. 


\section{DISCLAIMER}

Portions of this document may be illegible electronic image products. Images are produced from the best available original document. 


\section{Introduction}

Over the last several decades many experiments have been conceived to study the ignition of pulverized coal and other solid fuels. We are constructing a laser-based apparatus which offers several advantages over those currently in favor. Sieve-sized particles are dropped batch-wise into a laminar, upward-flow wind tunnel which is constructed with a quartz test section. The gas stream is not preheated. A single pulse from a Nd:YAG laser is focused through the tunnel and ignites several particles. The transparent test section and cool walls allow for application of two-color pyrometry to measure the particles' temperature history during ignition and combustion. Coals ranging in rank from lignites to low-volatile bituminous, and chars derived from these coals, will be studied in this project. For each fuel type, measurements of the ignition temperature under various experimental conditions (particle size and free-stream oxygen concentration), combined with a detailed analysis of the ignition process, will permit the determination of kinetic rate constants of ignition.

This technique offers many advantages over conventional drop-tube furnace experiments. One is the ability to directly measure ignition temperature rather than inferring it from measurements of the minimum gas temperature needed to induce ignition. Another advantage is the high heating rates achievable - on the order of $10^{6} \mathrm{~K} / \mathrm{s}$. This is a significant improvement over experiments which rely on convective heating from a hot gas, which typically achieves heating rates of $10^{4} \mathrm{~K} / \mathrm{s}$. The higher heating rate more closely simulates conditions in conventional coal combustors used for power generation.

It should be noted that single-particle behavior governs the conditions of this experiment; i.e., the particle suspension is dilute enough that particle-to-particle effects (other than radiative heat transfer) are not important. In actual combustors, particle loading, especially near the injector, is high enough that such "cooperative effects" dominate. Our approach is to gain a clear understanding of single-particle behavior with this experiment, before facing the more difficult problem encountered with cloud suspensions. 


\section{Objectives}

Our objectives for this project are:

1. Construction of the laser-ignition experiment, including:

1.1. gas delivery and regulation system;

1.2. wind tunnel;

1.3. exhaust system;

1.4. laser system and beam-guiding optics;

1.5. optical detection system; and

1.6. data acquisition and processing;

2. Shakedown testing of the various components;

3. Ignition of coals of various rank, from lignites to low-volatile bituminous;

4. Measurement of the ignition temperatures of these fuels under various experimental conditions (particle size and free-stream oxygen concentration);

5. Extraction of ignition rate constants from temperature measurements by application of an appropriate heterogeneous-ignition analysis.

\section{Accomplishments in This Quarter}

\section{Experiment}

During the past reporting period, we have been working on the development of the high-speed data-acquisition system to be used with the two-color pyrometry system for particle temperature measurement. After several attempts and failures at implementing a PC- $r$ based data-acquisition board for this purpose, we have decided to purchase, with department funding, to purchase an off-the-shelf data-acquisition system. We hope to have the system in place by the end of the calendar year.

In addition, we have been preparing a manuscript based on data we have obtained together with a new model developed to describe the ignition behavior of pulverized coals. The data were acquired by the previous graduate student, Mr. Subrahmanyam Musti, as part 
of his MS thesis. The model is a modification of a previous model developed by the PI, which describes ignition reactivity by assigning a distributed activation energy to the coals of a particular sample.

The final activity of the past reporting period is our presentation of research results at the Summer Annual Meeting of the American Chemical Society, held August 25 to 28, 1996, in Orlando, Florida.

\section{Goals for Next Quarter}

During the next reporting period, we will concentrate on the design and development of the two-color pyrometry system. We will complete specification of all optical components, filters, and detectors. Finally, we will complete the manuscript currently in preparation, and submit it to the journal, Energy and Fuels, for review. 